\title{
Humour
}

\section{The pediatric doctor mom blues}

when I woke up this mornin' I couldn't get out of bed I was twisted in the covers cat was sleepin' on my head the clock was reading 8:15 my clinic starts at 8 my husband turned off the clock alarm I'm gonna be so late I got those pediatric doctor mom doctor mom doctor mom blues...

I go downstairs for breakfast and feed the dog and cat no time for walks or exercise I know I'm gettin' fat the bread is gettin' mouldy the milk has all gone sour my son's used the hot water up how can I take a shower? the cereal box is empty the dog needs to go out my daughter wants cash for new jeans

or she is gonna pout I got those pediatric doctor mom doctor mom doctor mom blues...

my husband's on the telephone a transatlantic call morning paper's got an article: "how women can have it all" - no way!

forgot to gas the car up now the pointer's on the " $E$ " the kids have changed the radio to Sonic from CBC and now I'm stuck in traffic hit every single light it might be best to camp out in my office for the night I got those pediatric doctor mom doctor mom doctor mom blues...

my student didn't show up the resident's away the clinic's double-booked me guess it's twice as long a day

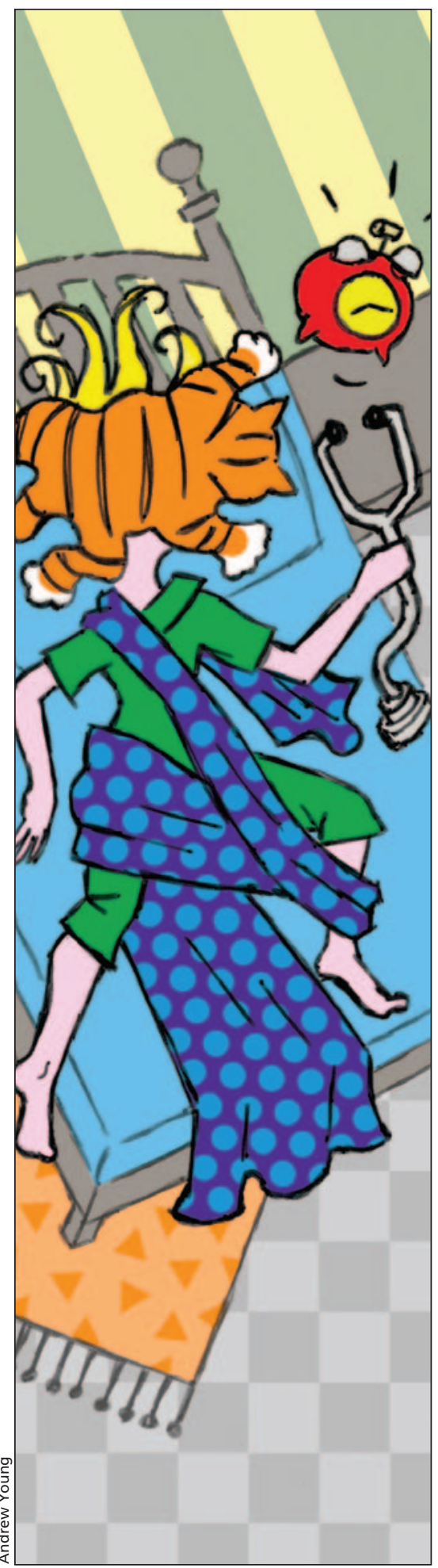

the first mom's got an attitude the next mom's runnin' late the next six kids got ADD I cannot concentrate the next kid is so whiny and his mother is depressed wanna chuck these charts behind me and go home for a rest but there's twenty nine dictations and prescriptions to call in med student evaluations some days you just can't win I got those pediatric doctor mom doctor mom doctor mom blues...

my work day's finally over my home work's just begun drive back and cook and clean the house no time to have some fun take Sara to her practice and put the laundry in the dishes in the dishwasher recycling in the bin then I pick her up from choir walk the dog around the block and go to sleep at midnight don't forget to set the clock and tomorrow when the sun comes up I'll wake up in my bed all tangled in the covers with a cat upon my head

I got those pediatric doctor mom doctor mom doctor mom blues...

I got those pediatric doctor mom doctor mom doctor mom blues....

\section{Debbi Andrews MD}

Divisional Head

Neurodevelopment/Neuromotor Paediatrics Faculty of Medicine

University of Alberta Edmonton, Alta.

This poem was an award winner in the University of Alberta Hospital's annual poetry contest in 2007. It is the happy result of the intersection of taking Shirley Serviss's poetry workshop, "Writing the Medical Experience," with the acquisition of a new cat. 